Research paper

\title{
The paradox of public holidays: Hospital-treated self-harm and associated factors
}

\author{
Eve Griffin $^{\mathrm{a}, *}$, Christina B. Dillon ${ }^{\mathrm{a}}$, Grace O'Regan ${ }^{\mathrm{a}}$, Paul Corcoran ${ }^{\mathrm{b}, \mathrm{c}}$, Ivan J. Perry ${ }^{\mathrm{b}}$, \\ Ella Arensman ${ }^{\mathrm{a}, \mathrm{b}}$

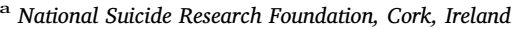 \\ b Department of Epidemiology and Public Health, University College Cork, Ireland \\ c Department of Obstetrics and Gynaecology, University College Cork, Ireland
}

\section{A R T I C L E I N F O}

\section{Keywords:}

Self-harm

Public holidays

Alcohol consumption

Mental health

\begin{abstract}
A B S T R A C T
Background: Recent research on the patterns of self-harm around public holidays is lacking. This study used national data to examine the patterns of hospital-treated self-harm during public holidays, and to examine associated factors.

Methods: Data on self-harm presentations to all emergency departments were obtained from the National SelfHarm Registry Ireland. The association between self-harm presentations and public holidays was examined using univariate and multivariate Poisson regression analyses.

Results: A total of 104,371 presentations of self-harm were recorded between 2007 and 2015. The mean number of self-harm presentations was 32 on public holidays. St. Patrick's Day had the highest number of presentations compared to all other public holidays, with a daily mean of 44 presentations. Across all years, self-harm presentations during public holidays had a $24 \%$ increased risk of involving alcohol consumption compared to all other days and this effect was most pronounced during the Christmas period. The association with alcohol remained significant at a multivariate level. Presentations on public holidays were more likely to attend out of normal working hours. An increase in male presentations involving self-cutting was observed on public holidays and there was an over-representation of males presenting for the first time.

Limitations: It is likely that extent of alcohol involvement in self-harm presentations reported here is an underestimate, as it was dependent on the information being recorded by the attending clinician.

Conclusions: Public holidays are associated with an elevated number of self-harm presentations to hospital, with presentations to hospital involving alcohol significantly increased on these days. Hospital resources should be targeted to address increases during public holidays, including during out-of-hours. Involvement of alcohol may delay delivery of care to these patients in emergency settings.
\end{abstract}

\section{Introduction}

The impact of self-harm in terms of morbidity and mortality is significant. An estimated 1 in 25 patients presenting to hospital for selfharm will die by suicide in the following 5 years, while the one-year rate of non-fatal repetition is 16\% (Carroll et al., 2014). Self-harm is now as much a public health issue as it is a mental health one, and prevention strategies focus on general awareness campaigns as well as interventions for high-risk groups (Hegerl et al., 2009; WHO, 2014). National descriptive data on hospital-treated self-harm have highlighted peaks in self-harm attendances to hospital emergency departments during national public holidays (Griffin et al., 2016) and this provides an opportunity to further research the patterns of self-harm during these periods of the year.

Previous research on the temporal variation of suicidal behaviour has primarily been concerned with the timing of suicides over the year (Beauchamp et al., 2014; Cavanagh et al., 2016; Corcoran et al., 2004). Few studies have explored these patterns in relation to self-harm focusing on general patterns of self-harm during public holidays (Jessen et al., 1999) or on specific holidays periods (e.g. Bergen and Hawton, 2007). Outcomes from these studies indicate that the incidence of selfharm is low in the days leading up to a holiday period, and increase at the end of the holiday period. The seasonal distribution of self-harm has also been investigated, but the findings are less consistent. Peaks in selfharm have been reported from early spring to late autumn (Jessen et al., 1999; Subba et al., 2009; Valtonen et al., 2006; Yip and Yang, 2004).

\footnotetext{
* Correspondence to: National Suicide Research Foundation, 4.28 Western Gateway Building, University College Cork, Ireland.

E-mail address: evegriffin@ucc.ie (E. Griffin).
} 
Two studies from England found significant associations between suicide and self-harm around the Christmas period (Bergen and Hawton, 2007; Cavanagh et al., 2016).

In particular, recent research on this topic is lacking. Previous studies have been limited by sample size, a focus on specific holiday periods or not adjusting for seasonal trends or characteristics of the selfharm act. Importantly, the factors associated with increased peaks during public holidays have not been well explored. Alcohol is frequently involved in self-harm acts (Ness et al., 2015; Perry et al., 2012) and evidence indicates that there are seasonal variations in alcohol consumption (Silm and Ahas, 2005). Alcohol has been shown to be a common feature of public holidays (Bellis et al., 2015; Jessen et al., 1999; Lloyd et al., 2013), however evidence to support the relationship between alcohol consumption and self-harm during public holidays is limited (Bergen and Hawton, 2007). Sex differences in relation to seasonality have also been reported, but the findings are contradictory (Preti and Miotto, 1998; Valtonen et al., 2006).

This is the first study to use national data to examine the patterns of hospital-treated self-harm during public holidays as well as associated factors. The specific aims of this study were to investigate the prevalence of self-harm during public holidays compared to other days, and to examine the factors associated with self-harm during public holidays.

\section{Methods}

\subsection{National Self-Harm Registry Ireland}

Data on self-harm presentations to all emergency departments (EDs) from January 2007 to December 2015 were obtained from the National Self-Harm Registry Ireland. The Registry is a national system that records and monitors all self-harm presentations to EDs across the Republic of Ireland. Data are collected by data registration officers using standardised case-definitions and inclusion and exclusion criteria. A case of self-harm is defined as "an act with non-fatal outcome in which an individual deliberately initiates a non-habitual behaviour, that without intervention from others will cause self-harm, or deliberately ingests a substance in excess of the prescribed or generally recognised therapeutic dosage, and which is aimed at realising changes that the person desires via the actual or expected physical consequences" (Platt et al., 1992). Self-harm cases are identified through a combination of manually checking consecutive presentations to EDs, selecting potential cases on the basis of keyword searches and triage coding by hospital staff.

\subsection{Self-harm data}

The Registry has a core dataset including: sex, age, day and hour of attendance at hospital and method(s) of self-harm according to the tenth revision of the WHO's International Classification of Disease codes for intentional injury (X60-X84). Whether or not alcohol was consumed as part of the self-harm act was ascertained through hospital case notes - if it was recorded on registration by the attending clinician or if present on toxicology reports.

\subsection{Public holidays}

There are nine official public holidays in Ireland each year: four bank holidays (first Monday in May, June and August and last Monday in October); New Year's Day (1st January); St. Patrick's Day (17th March); Easter Monday; Christmas Day (25th December) and St. Stephen's Day (26th December). The following days were also included: Good Friday, Easter Saturday and Easter Sunday; Christmas Eve (24th December); New Year's Eve (31st December). In order to attribute alcohol-related attendances in the early hours of the morning to the preceding evening we defined a day as running from 6 am to 6 am instead of $12 \mathrm{am}$ to $12 \mathrm{am}$ - a technique previously used (e.g. Foster et al., 2015).

\subsection{Statistical analyses}

Descriptive analyses were used to examine patterns of self-harm presentations across public holidays compared to all other days in the year. Univariate Poisson regression analyses were used to explore the association between self-harm and alcohol consumption on public holidays at a univariate level. Multivariate Poisson regression analyses were subsequently performed to identify the factors independently associated with self-harm presentations during public holidays, providing Risk Ratios (RR). These analyses were stratified by sex and adjusted for year of presentation, season and day of the week. Both univariate and multivariate analyses were replicated for the day preceding (lead) and following (lag) a public holiday where non-consecutive events occurred, as outlined by Lloyd et al. (2013), to establish whether observed associations were found in the days around the public holiday itself. Statistical analyses were completed using Stata version 12.

\subsection{Ethical approval}

The National Research Ethics Committee of the Faculty of Public Health Medicine, Dublin granted ethical approval for the National SelfHarm Registry Ireland. The Registry has also received ethical approval from the relevant hospitals and Health Service Executive (HSE) ethics committees.

\section{Results}

\subsection{Descriptive statistics}

A total of 104,371 presentations of self-harm were recorded between January 1st, 2007 and December 31st, 2015. The majority of presentations were made by females $(n=56,215 ; 54 \%)$ and almost twothirds ( $n=96,150 ; 92 \%)$ were aged under 55 years. The most common method of self-harm recorded was intentional drug overdose ( $n=72,391 ; 69 \%$ ) followed by self-cutting ( $n=24,587 ; 24 \%)$. While rare as a sole method of self-harm, alcohol was present in $38 \%$ of presentations $(n=39,949)$ and more common among males than females ( $42 \%$ vs. $35 \%$; $\left.X^{2}(1) 395.52, \mathrm{p}<0.001\right)$.

The occurrence of self-harm presentations varied according to day of the week. The number of presentations steadily increased over the course of the week for both males and females, peaking on Sundays and Mondays. This was more pronounced when alcohol was involved and for female presentations (see Fig. 1). Alcohol involvement was most common among presentations made on Saturdays and Sundays $(44 \%$ for males and $41 \%$ for females).

\subsection{Self-harm presentations on public holidays}

The mean number of self-harm presentations was 32 (15 for males and 17 for females) on public holidays and 27 (13 for males and 15 for females) on all other days. Across all years, St. Patrick's Day had the highest number of presentations compared to all other public holidays, with a mean of 44 presentations (21 for males and 23 for females). New Year's Day had a mean of 41 presentations (males: 20; females: 21). Despite this overall increase in presentations on public holidays, the Christmas period was associated with a decreased number of presentations. The mean number of presentations on Christmas Eve was 22 (males: 11; females:11) and for Christmas Day was 23 (males:10; females 13) (see Table 1).

Alcohol was present in $43 \%$ of all self-harm presentations on public holidays compared to $38 \%$ on all other days $\left[X^{2}=42.8, \mathrm{p}<0.001\right]$. Self-harm presentations during public holidays had a $24 \%$ increased risk of involving alcohol [Risk Ratio (RR): 1.24; 95\% Confidence 

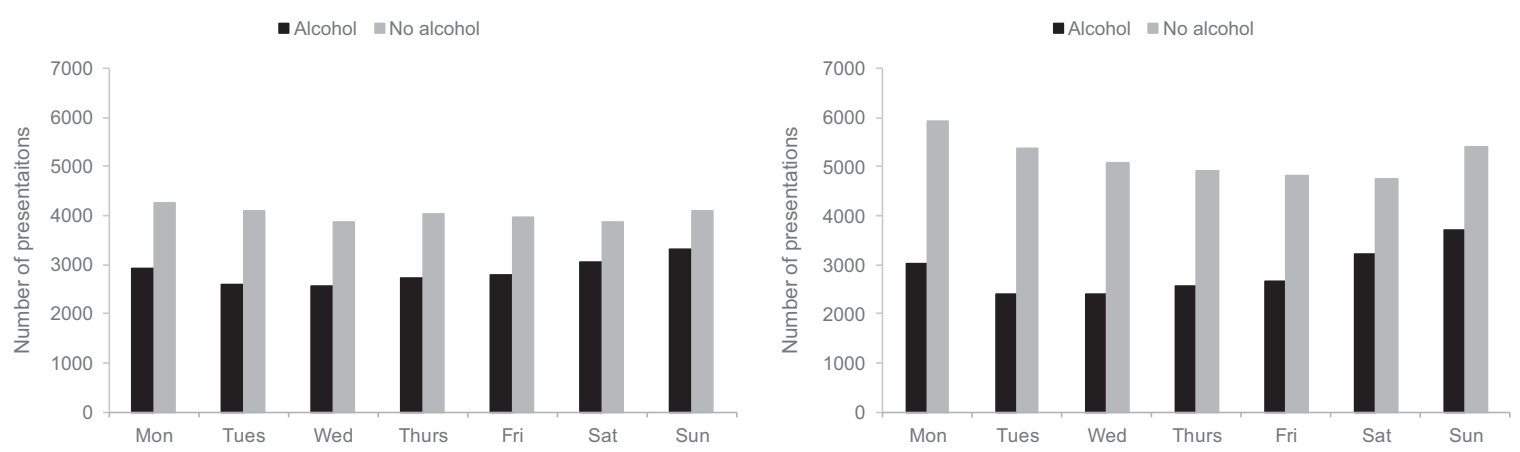

Fig. 1. Number of self-harm presentations according to day of week by alcohol involvement for males (left) and females (right).

Interval (CI): 1.17-1.32] compared with all other days. This pattern was observed for both male (RR:1.22, 95\% CI: 1.12-1.34) and female (1.251.15-1.36) presentations.

When public holidays were examined individually, alcohol consumption was most strongly associated with the Christmas holiday period. For males, an increased risk of alcohol involvement was found for presentations to hospital on New Year's Day $(+53 \%)$, June Bank Holiday $(+88 \%)$, Christmas Eve $(+150 \%)$ and Christmas Day $(+81 \%)$. For females, similar increased risk was found for New Year's Day $(+37 \%)$ and Christmas Day ( $+79 \%)$. In addition, significant increased risk was found on St Stephen's Day $(+62 \%)$, New Year's Eve $(+102 \%)$, St. Patrick's Day $(+62 \%)$ and Easter Sunday $(+58 \%)$. An increased risk of alcohol involvement was also observed on New Year's Eve $(+62 \%)$ and New Year's Day ( $+45 \%)$. Good Friday was the only public holiday associated with a decreased risk of alcohol involvement ( $-25 \%)$, but significance did not hold when males and females were considered separately (Table 1).

\subsection{Factors associated with self-harm presentations on public holidays}

Controlling for other variables, alcohol was the most important factor distinguishing self-harm presentations during public holidays, compared to all other days. For males, self-harm presentations had a $21 \%$ increased risk of alcohol involvement $(1.21,1.10-1.34)$ and for females the increased risk was $17 \%(1.17,1.06-1.29)$. Presentations on these days were more likely to occur out-of-hours, between 12 am and $9 \mathrm{am}$ [males (1.15, 1.04-1.27); females (1.35, 1.20-1.51)].
Presentations by males were more likely to arrive to the ED by ambulance during public holidays (1.15, 1.04-1.27). An increased risk of first presentations as a result of self-harm by males on public holidays was also observed $(1.16,1.05-1.29)$. Increased associations for presentations involving self-cutting (1.21, 1.07-1.37). Age was associated with public holiday presentations for females only. Compared with those aged 55 years and over, presentations by those aged 15 years and under were less likely $(0.58,0.41-0.82)$ (Table 2$)$.

\subsection{Sensitivity analysis}

We replicated analyses for the day prior to (lead) and following (lag) each public holiday. No associations were significant at $\mathrm{p}<0.01$, suggesting that the observed characteristics were unique to the public holidays themselves.

\section{Discussion}

\subsection{Summary of main findings}

This study explored the variation of self-harm presentations to hospital on public holidays and identified the factors associated with such variation. We found that self-harm presentations varied according to day of the week - highest on Sundays and Mondays. Considering variation across the year, public holidays were associated with an increased number of self-harm presentations to hospital emergency departments, with an average of 32 presentations per day on public

Table 1

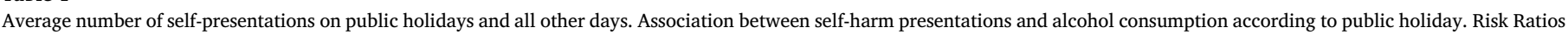
(RR) with $95 \%$ confidence intervals (CI) are presented from univariate analyses, stratified by sex.

\begin{tabular}{|c|c|c|c|c|c|c|c|c|c|}
\hline & \multicolumn{3}{|l|}{ Male } & \multicolumn{3}{|c|}{ Female } & \multicolumn{3}{|l|}{ All } \\
\hline & Mean & $\%$ Alcohol & RR (95\% CI) & Mean & $\%$ Alcohol & $\mathrm{RR}(95 \% \mathrm{CI})$ & Mean & $\%$ Alcohol & RR $(95 \% \mathrm{CI})$ \\
\hline All other days & 13 & $41.3 \%$ & - & 15 & $35.3 \%$ & - & 27 & $38.1 \%$ & - \\
\hline All public holidays & 15 & $46.5 \%$ & $1.22(1.12-1.34)^{* 2 * k}$ & 17 & $40.7 \%$ & $1.25(1.15-1.36)^{3.16 / 2}$ & 32 & $43.2 \%$ & $1.24(1.17-1.32)^{k+k x}$ \\
\hline New Year's Day (January 1st) & 20 & $52.0 \%$ & $1.53(1.15-2.03)^{\text {k. }}$ & 21 & $43.0 \%$ & $1.37(1.04-1.81)^{*}$ & 41 & $46.9 \%$ & $1.45(1.19-1.77)$ \\
\hline St. Patricks Day (March 17th) & 21 & $44.6 \%$ & $1.14(0.86-1.50)$ & 23 & $47.1 \%$ & $1.62(1.23-2.12)^{k}$ & 44 & $45.7 \%$ & $1.37(1.13-1.66)^{k \text { k.t }}$ \\
\hline Good Friday & 13 & $35.5 \%$ & $0.78(0.54-1.13)$ & 13 & $27.7 \%$ & $0.70(0.47-1.04)$ & 26 & $31.5 \%$ & $0.75(0.60-0.98)^{*}$ \\
\hline Easter Saturday & 14 & $47.2 \%$ & $1.26(0.88-1.79)$ & 17 & $37.3 \%$ & $1.08(0.79-1.49)$ & 31 & $41.9 \%$ & $1.15(0.91-1.46)$ \\
\hline Easter Sunday & 16 & $46.8 \%$ & $1.24(0.90-1.70)$ & 19 & $46.5 \%$ & $1.58(1.17-2.13)^{\text {sike }}$ & 35 & $46.2 \%$ & $1.41(1.13-1.75)^{* * *}$ \\
\hline Easter Monday & 15 & $38.7 \%$ & $0.89(0.63-1.26)$ & 20 & $36.5 \%$ & $1.04(0.77-1.42)$ & 35 & $37.5 \%$ & $0.97(0.77-1.22)$ \\
\hline May Bank Holiday & 14 & $36.4 \%$ & $0.81(0.56-1.16)$ & 18 & $33.1 \%$ & $0.90(0.65-1.24)$ & 32 & $34.8 \%$ & $0.85(0.67-1.08)$ \\
\hline June Bank Holiday & 14 & $57.1 \%$ & $1.88(1.33-2.65)^{\text {thet }}$ & 15 & $30.9 \%$ & $0.81(0.57-1.16)$ & 29 & $42.8 \%$ & $1.25(0.99-1.59)$ \\
\hline August Bank Holiday & 15 & $47.9 \%$ & $1.30(0.94-1.80)$ & 18 & $39.0 \%$ & $1.16(0.85-1.59)$ & 33 & $43.6 \%$ & $1.23(0.98-1.53)$ \\
\hline October Bank Holiday & 12 & $32.4 \%$ & $0.68(0.45-1.01)$ & 15 & $34.3 \%$ & $0.95(0.67-1.34)$ & 27 & $32.8 \%$ & $0.81(0.62-1.05)$ \\
\hline Christmas Eve (December 24th) & 11 & $64.1 \%$ & $2.51(1.70-3.73)^{\text {*. }}$ & 11 & $41.2 \%$ & $1.27(0.86-1.89)$ & 22 & $52.5 \%$ & $1.80(1.37-2.35)^{*+* k}$ \\
\hline Christmas Day (December 25th) & 10 & $56.2 \%$ & $1.81(1.18-2.76)^{* * *}$ & 13 & $49.6 \%$ & $1.79(1.25-2.55)^{k * k}$ & 23 & $51.9 \%$ & 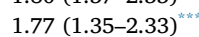 \\
\hline St. Stephen's Day (December 26th) & 17 & $47.1 \%$ & $1.25(0.91-1.72)$ & 17 & $47.1 \%$ & $1.62(1.18-2.22)^{* k x}$ & 33 & $47.0 \%$ & $1.44(1.15-1.79)^{k * k}$ \\
\hline New Year's Eve (December 31st) & 17 & $47.5 \%$ & $1.27(0.93-1.74)$ & 18 & $52.7 \%$ & $2.02(1.50-2.72)^{3(x+k}$ & 35 & $50.0 \%$ & $1.62(1.31-2.01)^{\text {k.k.k }}$ \\
\hline
\end{tabular}

\footnotetext{
* $\mathrm{p}<0.05$

$* * \mathrm{p}<0.01$

$* * * \mathrm{p}<0.001$.
} 
Table 2

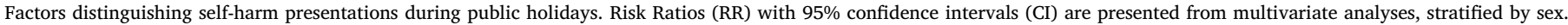

\begin{tabular}{|c|c|c|c|c|c|c|}
\hline & \multicolumn{3}{|l|}{ Male } & \multicolumn{3}{|l|}{ Female } \\
\hline & All other days & Public holidays & $\mathrm{RR}(95 \% \mathrm{CI})^{\mathrm{a}}$ & All other days & Public holidays & $\mathrm{RR}(95 \% \mathrm{CI})^{\mathrm{a}}$ \\
\hline Alcohol present $(\mathrm{ref}=\mathrm{no})$ & $19,088(41.3 \%)$ & $901(46.5 \%)$ & $1.21(1.10-1.34)^{k+k * * *}$ & $19,070(35.3 \%)$ & $890(40.7 \%)$ & $1.17(1.06-1.29)^{k . *}$ \\
\hline \multicolumn{7}{|l|}{ Age } \\
\hline$<15 y r s$ & $577(1.3 \%)$ & $19(1.0 \%)$ & $0.77(0.44-1.36)$ & $1864(3.5 \%)$ & $42(1.9 \%)$ & $0.58(0.41-0.82)^{\text {k*t. }}$ \\
\hline $15-24 y r s$ & $13,613(29.5 \%)$ & $584(30.1 \%)$ & $1.02(0.83-1.26)$ & $16,864(31.2 \%)$ & $685(31.4 \%)$ & $0.91(0.77-1.08)$ \\
\hline $25-54 y r s$ & $28,622(61.9 \%)$ & $1199(61.8 \%)$ & $1.01(0.83-1.23)$ & $30,831(57.1 \%)$ & $1272(58.2 \%)$ & $0.90(0.77-1.06)$ \\
\hline $55+y r s$ & $3405(7.4 \%)$ & $137(7.1 \%)$ & Ref & $4493(8.3 \%)$ & $186(8.5 \%)$ & Ref \\
\hline \multicolumn{7}{|l|}{ Time of presentation } \\
\hline $9 \mathrm{am}-6 \mathrm{pm}$ & $14,690(31.8 \%)$ & $566(29.2 \%)$ & Ref & $18,374(34.0 \%)$ & $634(29.0 \%)$ & Ref \\
\hline $6 \mathrm{pm}-12 \mathrm{am}$ & $15,552(33.7 \%)$ & $614(31.7 \%)$ & $0.98(0.86-1.11)$ & $18,429(34.1 \%)$ & $702(32.1 \%)$ & $1.09(0.97-1.22)$ \\
\hline $12 \mathrm{am}-9 \mathrm{am}$ & $15,975(34.6 \%)$ & $759(39.1 \%)$ & $1.15(1.02-1.30)^{*}$ & $17,227(31.9 \%)$ & $849(38.9 \%)$ & $1.35(1.20-1.51)^{1 . * * \times x}$ \\
\hline Brought by ambulance $(\mathrm{ref}=\mathrm{no})$ & $26,823(60.6 \%)$ & $1195(64.1 \%)$ & $1.15(1.04-1.27)^{k . k}$ & $29,076(56.1 \%)$ & $1250(59.4 \%)$ & $1.06(0.96-1.16)$ \\
\hline First presentation $(\mathrm{ref}=\mathrm{no})$ & $28,970(62.7 \%)$ & $1286(66.3 \%)$ & $1.16(1.05-1.29)^{. . k t}$ & $33,244(61.5 \%)$ & $1412(64.6 \%)$ & $1.09(0.99-1.21)$ \\
\hline \multicolumn{7}{|l|}{ Method } \\
\hline Drug overdose only & $25,230(54.6 \%)$ & $1013(52.2 \%)$ & Ref & $37,352(69.1 \%)$ & $1544(70.7 \%)$ & Ref \\
\hline Self-cutting only & $9325(20.1 \%)$ & $433(22.3 \%)$ & $1.21(1.07-1.37)^{\text {skte }}$ & $8412(15.6 \%)$ & $317(14.5 \%)$ & $0.96(0.84-1.10)$ \\
\hline Drug overdose and self-cutting & $2068(4.5 \%)$ & $79(4.1 \%)$ & $0.93(0.72-1.19)$ & $2371(4.4 \%)$ & $90(4.1 \%)$ & $0.98(0.78-1.22)$ \\
\hline Attempted hanging & $2944(6.4 \%)$ & $120(6.2 \%)$ & $1.18(0.97-1.43)$ & $1200(2.2 \%)$ & $57(2.6 \%)$ & $1.28(0.97-1.68)$ \\
\hline Attempted drowning & $1295(2.8 \%)$ & $59(3.0 \%)$ & $1.14(0.87-1.51)$ & $902(1.7 \%)$ & $29(1.3 \%)$ & $0.69(0.45-1.03)$ \\
\hline Other & $5377(11.6 \%)$ & $235(12.1 \%)$ & $1.15(0.99-1.34)$ & $3793(7.0 \%)$ & $148(6.8 \%)$ & $1.01(0.85-1.20)$ \\
\hline
\end{tabular}

${ }^{\text {a }}$ Adjusted for year, weekend presentation, season

* $\mathrm{p}<0.05$

$* * \mathrm{p}<0.01$

$* * * \mathrm{p}<0.001$

holidays. In particular, presentations were highest on St. Patrick's Day, the national holiday in Ireland. The consumption of alcohol at the time of self-harm was also elevated on public holidays, with an increased risk of $24 \%$ on these days. Presentations on public holidays were more likely to occur out of normal working hours. An over-representation of persons presenting for the first time was also observed. For males, the increase was uniform across all ages while for females, presentations by those aged under 15 years were less likely to occur.

\subsection{Interpretation}

Our findings confirm previously reported temporal patterns in selfharm, demonstrating an overall increase in hospital-treated self-harm on public holidays (e.g. Jessen et al., 1999). Consistent with previous research, a reduced number of self-harm presentations were observed around the Christmas period (Jessen et al., 1999; Bergen and Hawton, 2007). The observed peak in attendances around the New Year has also been reported elsewhere for suicide and self-harm occurrences (Jessen et al., 1999; Ploderl et al., 2015; Cavanagh et al., 2016). We have coined this observed pattern a 'paradox' of public holidays - while such days are generally perceived as a period of celebration or non-work, they may in fact be times of increased risk for self-harm among vulnerable individuals.

This is the first comprehensive study to identify factors associated with these patterns of attendances during public holidays. While we cannot infer causation, we found that alcohol was the most important factor distinguishing self-harm presentations on public holidays. The relationship between self-harm and alcohol misuse has been well established (Ness et al., 2015). The increased risk of alcohol being present in self-harm presentations on public holidays that we found may suggest that there are more impulsive and aggressive self-harm acts occurring on these days. This is further supported by the findings that ED presentations on public holidays are more likely to be made by persons presenting for the first time with self-harm. We also found an increase in presentations by males brought by ambulance on these days. Previous research has failed to find a pattern of seasonality with regard to methods of self-harm (Ajdacic-Gross et al., 2003). We found that for males only, presentations involving self-cutting increased during pub- lic-holidays. Self-cutting is associated with impulsivity (Rodham et al., 2004) and a high risk of repetition (Arensman et al., 2014). In particular, males presenting with self-cutting are more likely to receive more intensive medical treatment and to re-present within 12 months with a highly-lethal method of self-harm (Larkin et al., 2014).

Despite the decrease in self-harm presentations around the Christmas period, presentations made during this period were more likely to involve alcohol. A more sustained effect was observed for females. Other studies have postulated the decreased patterns of suicidal behaviour around Christmas to be as a result of increased social connectedness during this time, with an increase around the New Year linked to the 'Broken-Promise Effect' (Gabennesch, 1988). Our results showed that self-harm involving alcohol was most strongly linked to the Christmas period, suggesting that it is still a period which may impact negatively on persons with underlying mental health issues.

\subsection{Strengths and limitations}

To our knowledge, this study is the first to examine the patterns of suicidal behaviour during public holidays using data from a national self-harm registry. Therefore, all presentations to hospital EDs during the period 2007-2015 were included. Furthermore, we were able to explore the factors associated with attendances on these days, compared to all other days, to provide some explanation as to the observed differences. In particular alcohol has emerged as an important factor contributing to the observed pattern of attendances. We also adjusted the analysis to ensure that alcohol-related presentations made in the early hours of the morning were attributed to the preceding day. To test whether the observed effects were spread around the public holidays, we replicated the analyses for the days preceding and following each public holiday. This sensitivity analysis suggested that the outcomes observed were unique to the public holidays. However, our study also had some limitations. The involvement of alcohol at the time of the selfharm act was ascertained via clinical notes in each hospital. Consequently, in most cases there was no precise and objective information about the amount of alcohol consumed (e.g. blood alcohol content) and the recording of alcohol by the Registry was dependent on 
this information being recorded by the attending clinician. To this end, it is likely that percentages reported here underestimate the extent of alcohol involvement in self-harm.

\subsection{Implications}

These findings have important implications for emergency services around public holidays. An increase in alcohol-related presentations, along with an increase in male presentations brought by ambulance during these periods and out-of-hours attendances may contribute to the demands within an emergency department. Such presentations may be challenging for hospital staff to manage. Increased attendances involving alcohol may lead to delayed assessment for some patients. Adequate staffing and resources should be in place around these periods during the year in order to ensure that these presentations are managed in line with international guidelines (NICE, 2004).

Other studies have reported an increased occurrence of accidents and emergency attendances with alcohol intoxication around public holidays (Foster et al., 2015; Lloyd et al., 2013) and increased consumption of alcohol around these times (Bellis et al., 2015). These findings suggest that vulnerable groups are at particular risk during public holidays, with an increase in people presenting to hospital EDs for the first time with self-harm. To this end, public health activities can play a role in addressing this issue. General population campaigns and strategies to target alcohol consumption may be important in reducing risk of suicidal behaviour, particularly those targeting specific periods and groups (Liang et al., 2016; Neighbors et al., 2007). Emerging research has shown that short-term alcohol restrictions are associated with fewer alcohol-related injury emergency presentations (Liang et al., 2016). At a univariate level, we found a decreased risk of alcoholrelated self-harm on Good Friday, one of the days in Ireland where trading of alcohol is prohibited. The mean number of self-harm presentations on this day also reduced. Further research should formally evaluate the impact of strategies addressing alcohol misuse, such as minimum pricing, labelling and advertising restrictions, on selfharm presentations involving alcohol.

\section{References}

Ajdacic-Gross, V., Wang, J., Bopp, M., Eich, D., Rössler, W., Gutzwiller, F., 2003. Are seasonalities in suicide dependent on suicide methods? A reappraisal. Soc. Sci. Med. 57, 1173-1181.

Arensman, E., Larkin, C., Corcoran, P., Reulbach, U., Perry, I.J., 2014. Factors associated with self-cutting as a method of self-harm: findings from the Irish National Registry of Deliberate Self-Harm. Eur. J. Public Health 24, 292-297.

Beauchamp, G.A., Ho, M.L., Yin, S., 2014. Variation in suicide occurrence by day and during major American holidays. J. Emerg. Med. 46, 776-781.

Bellis, M.A., Hughes, K., Jones, L., Morleo, M., Nicholls, J., McCoy, E., Webster, J. Sumnall, H., 2015. Holidays, celebrations, and commiserations: measuring drinking during feasting and fasting to improve national and individual estimates of alcohol consumption. BMC Med. 13, 113.

Bergen, H., Hawton, K., 2007. Variation in deliberate self-harm around Christmas and New Year. Soc. Sci. Med. 65, 855-867.

Carroll, R., Metcalfe, C., Gunnell, D., 2014. Hospital presenting self-harm and risk of fatal and non-fatal repetition: systematic review and meta-analysis. PLoS One 9, e89944.
Cavanagh, B., Ibrahim, S., Roscoe, A., Bickley, H., While, D., Windfuhr, K., Appleby, L., Kapur, N., 2016. The timing of general population and patient suicide in England, 1997-2012. J. Affect. Disord. 197, 175-181.

Corcoran, P., Reilly, M., Salim, A., Brennan, A., Keeley, H.S., Perry, I.J., 2004. Temporal variation in Irish suicide rates. Suicide Life Threat. Behav. 34, 429-438.

Foster, S., Gmel, G., Estevez, N., Bahler, C., Mohler-Kuo, M., 2015. Temporal patterns of alcohol consumption and alcohol-related road accidents in young Swiss men: seasonal, weekday and public holiday effects. Alcohol. Alcohol. 50, 565-572.

Gabennesch, H., 1988. When promises fail: a theory of temporal fluctuations in suicide. Soc. Forces 67, 129-145.

Griffin, E., Arensman, E., Corcoran, P., Dillon, C.B., Perry, I.J., 2016. National Self-Harm Registry Ireland Annual Report 2015. National Suicide Research Foundation, Cork.

Hegerl, U., Wittenburg, L., Arensman, E., Van Audenhove, C., Coyne, J.C., McDaid, D., Feltz-Cornelis, C.M., v.d., Gusmão, R., Kopp, M., Maxwell, M., Meise, U., Roskar, S., Sarchiapone, M., Schmidtke, A., Värnik, A., Bramesfeld, A., 2009. Optimizing Suicide Prevention Programs and Their Implementation in Europe (OSPI Europe): an evidence-based multi-level approach. BMC Public Health 9, 428.

Jessen, G., Jensen, B.F., Arensman, E., Bib-Brahe, U., Crepet, P., Leo, D.D., Hawton, K., Haring, C., Hjelmeland, H., Michel, K., Ostamo, A., Salander-Renberg, E., Schmidtke, A., Temesvary, B., Wasserman, D., 1999. Attempted suicide and major public holidays in Europe: findings from the WHO/EURO Multicentre Study on Parasuicide. Acta Psychiatr. Scand. 99, 412-418.

Larkin, C., Corcoran, P., Perry, I., Arensman, E., 2014. Severity of hospital-treated selfcutting and risk of future self-harm: a national registry study. J. Ment. Health 23, 115-119.

Liang, W., Gilmore, W., Chikritzhs, T., 2016. The effect of short-term alcohol restriction on risk of alcohol-related injury: a state wide population-based study. Int. J. Drug Policy 28, 55-59.

Lloyd, B., Matthews, S., Livingston, M., Jayasekara, H., Smith, K., 2013. Alcohol intoxication in the context of major public holidays, sporting and social events: a time-series analysis in Melbourne, Australia, 2000-2009. Addiction 108, 701-709.

National Institude of Clinical Excellence (NICE), 2004. Self-harm in over 8s: short-term management and prevention of recurrence. Clin. Guidel. [CG16].

Neighbors, C., Walters, S.T., Lee, C.M., Vader, A.M., Vehige, T., Szigethy, T., DeJong, W. 2007. Event-specific prevention: addressing college student drinking during known windows of risk. Addict. Behav. 32, 2667-2680.

Ness, J., Hawton, K., Bergen, H., Cooper, J., Steeg, S., Kapur, N., Clarke, M., Waters, K., 2015. Alcohol use and misuse, self-harm and subsequent mortality: an epidemiological and longitudinal study from the multicentre study of self-harm in England. Emerg. Med. J. 32, 793-799.

Perry, I.J., Corcoran, P., Fitzgerald, A.P., Keeley, H.S., Reulbach, U., Arensman, E., 2012. The incidence and repetition of hospital-treated deliberate self harm: findings from the world's first national registry. PLoS ONE 7, e31663.

Platt, S., Bille-Brahe, U., Kerkhof, A., Schmidtke, A., Bjerke, T., Crepet, P., Leo, D.D., Haring, C., Lonnqvist, J., Michel, K., 1992. Parasiticide in Europe: the WHO/EURO multicentre study on parasuicide. I. Introduction and preliminary analysis for 1989. Acta Psychiatr. Scand. 85, 97-104.

Ploderl, M., Fartacek, C., Kunrath, S., Pichler, E.M., Fartacek, R., Datz, C., Niederseer, D., 2015. Nothing like Christmas-suicides during Christmas and other holidays in Austria. Eur. J. Public Health 25, 410-413.

Preti, A., Miotto, P., 1998. Seasonality in suicides: the influence of suicide method, gender and age on suicide distribution in Italy. Psychiatry Res. 81, 219-231.

Rodham, K., Hawton, K., Evans, E., 2004. Reasons for deliberate self harm: comparison of self-poisoners and self-cutters in a community sample of adolescents. J. Am. Acad. Child Adolesc. Psychiatry 43, 80-87.

Silm, S., Ahas, R., 2005. Seasonality of alcohol-related phenomena in Estonia. Int. J. Biometeorol. 49, 215-223.

Subba, S.H., Binu, V.S., Menezes, R.G., Kanchan, T., Arun, M., Patil, R., Pant, S., Saha, A., De, A., Rana, M.S., 2009. Pattern and trend of deliberate self-harm in western Nepal. J. Forensic Sci. 54, 704-707.

Valtonen, H., Suominen, K., Partonen, T., Ostamo, A., Lönnqvist, J., 2006. Time patterns of attempted suicide. J. Affect. Disord. 90, 201-207.

World Health Organization (WHO), 2014. Preventing. Suicide: A global imperative. World Health Organization, Geneva.

Yip, P.S.F., Yang, K.C.T., 2004. A comparison of seasonal variation between suicide deaths and attempts in Hong Kong SAR. J. Affect. Disord. 81, 251-257. 